Wassermann reaction in peripheral blood of patients with secondary syphilis and human-immunodeficiency virus infection

In recent years there have been sporadic reports of unusual manifestations of syphilis ${ }^{1-3}$ and altered syphilis serology in AIDS patients. ${ }^{45} \mathrm{~A}$ recent study from Baltimore ${ }^{6}$ showed no indications of a changed clinical pattern of syphilis in HIV infected patients. More remarkably, an increased plasma reagin (RPR) titre as compared with HIV negative syphilis patients was found. In order to evaluate the lipid serology of patients with syphilis co-infected with HIV we performed a retrospective study of syphilis cases seen at our STD clinic in Copenhagen from 1985 to 1991. The following criteria were used for selection: patients with secondary syphilis being their first episode of the infection, as earlier infections may alter the lipid serology; patients with asymptomatic HIV infection; patients who received the full penicillin treatment and turned up for regular control until the Wassermann reaction (WR) in peripheral blood was zero. Of 15 asymptomatic HIV positive patients six fulfilled these criteria, all of them being homosexual men with a mean age of 29 years (range 25 to 42 ). As a control group HIV-antibody negative patients with secondary syphilis, were selected. Of 11 patients, seven fulfilled the criteria for selection. They were heterosexual males with a mean age of 38 years (range 26 to 52). All syphilis patients had a maculopapular rash typical for secondary syphilis, an increased WR titre in peripheral blood and positive antitreponemal tests (FTS-ABS, antiflagel IgG ELISA).

Treatment consisted of benzathine-penicillin G 2.4 million IU i.m. three times at weekly intervals ( 12 cases) and procaine penicillin 0.6 million IU/day for 10 days ( 1 case). The median WR titre prior to treatment was 13 (range 11 to 20 ) in the HIV/syphilis group

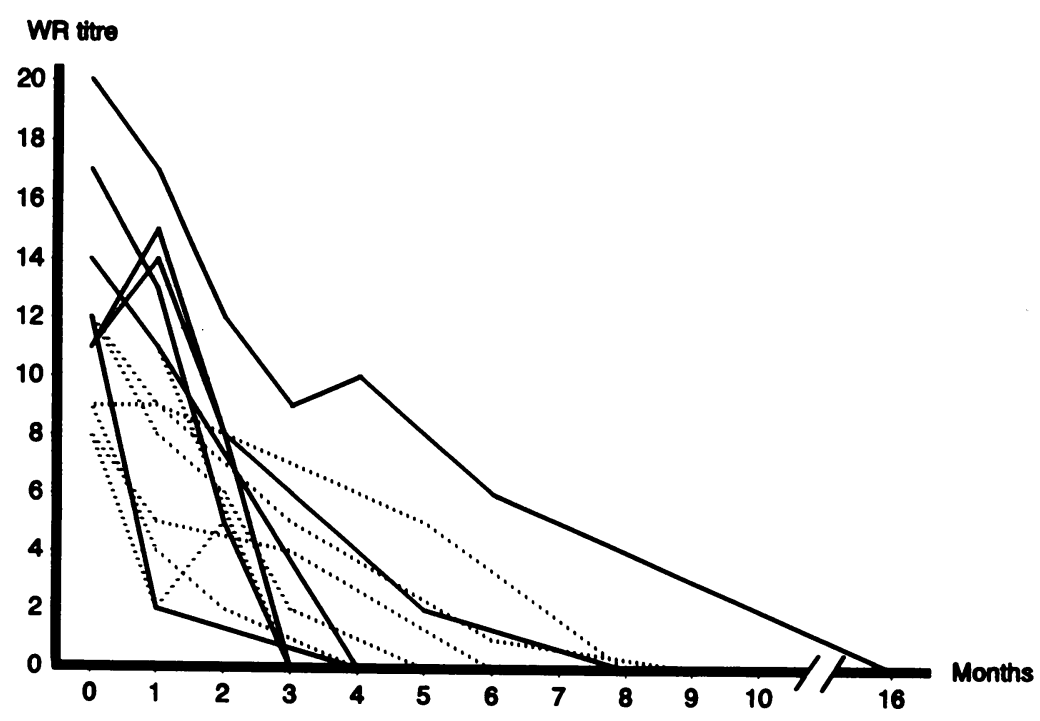

Figure Wassermann reaction (WR) in $6 \mathrm{HIV}$-antibody positive patients (solid lines) and $7 \mathrm{HIV}$-antibody negative patients with secondary syphilis at the time of diagnosis and following penjillin treatment. Note that the $x$-axis is broken between 10 and 16 months. and 9 ( 8 to 14 ) in the control group ( $p$ (twotailed) $=0 \cdot 1$, Mann-Whitney rank sum test) (fig).

There was no significant difference between the time in months of the two groups until WR was found non-reactive $(p=0 \cdot 8)$.

The decline in WR was as expected ${ }^{7}$; all patients had non-reactive WR titre within 16 months.

Thus, in this small study we found no indication of an altered clinical presentation of secondary syphilis in asymptomatic HIV infected patients, nor was there any difficulty in diagnosing syphilis serologically or monitoring the response to penicillin treatment in these patients.

KAARE WEISMANN LARS JELSTRUP PETERSEN CARSTEN SAND PETERSEN The Department of Dermatovenerology, Bispebjerg Hospital, University of Copenhagen, Bispebjerg Bakke 23, DK-2400 Copenhagen NV, Denmark
Cispebje Bake 23, DK-2400

1 Gregory N, Sanchez M, Buchness MR. The spectrum of syphilis in patients with human immunodeficiency virus infection. $\mathcal{F}$ Am Acad Dermatol 1990;22:1061-7.

2 Shulkin D, Tripoli L, Abell E. Lues maligna in a patient with human immunodeficiency virus infection. $A m \mathcal{J}$ Med 1988;85:425-7.

3 Cusini M, Zerboni S, Muratori S, Monti M, Alessi E. Atypical early syphilis in an HIV-infected homosexual male. Dermatologica $1988 ; 177: 300-4$

4 Hicks CB, Benson PM, Lupton GP, Tramont EC. Seronegative secondary syphilis in a patient infected Seronegative secondary syphilis in a patient infected
with the human immunodeficiency virus (HIV) with with the human immunodeficiency virus (HIV)

5 Tikjøb G, Russel M, Petersen CS, Gerstoft J, Kobayasi T. Seronegative secondary syphilis in a patient with AIDS identification of Treponema pallidum in a biopsy specimen. $\mathcal{F}$ Am Acad Dermatol 1991;24:506-8.

6 Hutchinson CM, Rompalo AM, Reichart CA, Hook EW Characteristics of patients with syphilis attending Baltimore STD clinics. Multiple high-risk subgroups and interactions with human immunodeficiency virus infection. Arch Intern Med 1991;151:511-6.

7 Fiumara NJ. Treatment of primary and secondary syphilis: serologic response. $f$ Am Acad Dermatol 1986; 14:487-91.

Accepted for publication 19 October 1992.

\section{Oro-anal sex and the occurrence of Kaposi's sarcoma}

There is epidemiological evidence that a sexually transmitted putative agent is responsible for the occurrence of Kaposi's sarcoma (KS) among HIV seropositive homosexual men. ${ }^{1}$ Based on their study among 65 homosexual men with AIDS in London, Beral et al ${ }^{2}$ reported that insertive oro-anal contact (active rimming) was strongly associated with $\mathrm{KS}$. Since this sexual practice involves direct oro-faecal contact it was hypothesised that such a putative agent would be present in faeces. To explore further this hypothesis, we investigated the occurrence of KS among approximately 1000 homosexual men who participate in our cohort study in Amsterdam, The Netherlands. ${ }^{3}$ Men are seen every three to six months and complete a questionnaire on their sexual lifestyle and related behaviours every half year. After the study started in 1984, 127 men were diagnosed with AIDS, of whom 97 had entered the study HIV seropositive and 30 had seroconverted for HIV antibodies during follow up. Of these 
Table Baseline sexual characteristics of AIDS cases with and without Kaposi's sarcoma in a cohort of homosexual men in Amsterdam, The Netherlands, 1984-1991

\begin{tabular}{|c|c|c|c|}
\hline Number of sexual partners & $\begin{array}{l}K S- \\
(n=101) \\
\operatorname{Mean}(S D)\end{array}$ & $\begin{array}{l}K S+ \\
(n=26) \\
\operatorname{Mean}(S D)\end{array}$ & \\
\hline $\begin{array}{l}\text { Lifetime } \\
\text { Last } 6 \text { months } \\
\text { Insertive anogenital } \\
\text { Receptive anogenital } \\
\text { Insertive oro-anal (active rimming) } \\
\text { Receptive oro-anal (passive rimming) } \\
\text { Use of nitrite (\%) }\end{array}$ & $\begin{array}{l}993(1000) \\
28(29) \\
10(15) \\
10(11) \\
4(6) \\
8(15) \\
70\end{array}$ & $\begin{array}{c}1178(600) \dagger \\
21(14) \\
11(12) \\
9(15) \\
6(14) \\
7(10) \\
71\end{array}$ & 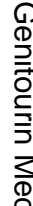 \\
\hline
\end{tabular}

* Number of lifetime partners preceding entry; other numbers of sexual partners and nitrite use (ever vs. never use) refer to behaviours during the 6 months preceding entry.

+ None of the differences were statistically significant.

men $26(20 \cdot 3 \%)$ were diagnosed with $\mathrm{KS}$ as AIDS defining condition. We compared baseline and subsequently gathered behavioural data among $\mathrm{KS}$ and non $\mathrm{KS}$ cases during the first 4 years of our study. No significant differences in the number of sexual partners with whom KS cases had practiced active rimming compared with non $\mathrm{KS}$ cases were present at any time. Also, no differences were found with respect to any other sexual or related variable. Baseline data regarding a selection of these variables are presented in the table. Among those who ever reported active rimming the percentage diagnosed with KS was almost exactly the same as among those who never reported active rimming $(22 \%$ vs $21 \%)$. Since this and three other cohort studies among homosexual $\operatorname{men}^{4-6}$ have failed to confirm the association between active rimming and the development of KS, the hypothesis needs to be reconsidered. Still, the epidemiology of HIV-related KS suggests a sexually transmitted cofactor in its aetiology.

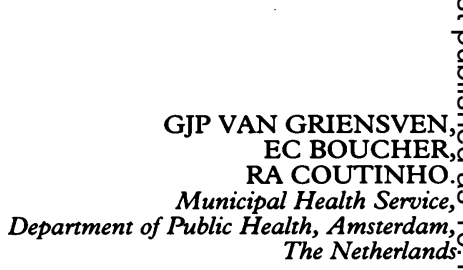

Address correspondence to: Dr G I P van Griensven, Dept of $\overrightarrow{ }$ Public Health \& Environment, Nieuwe Achtergracht 100 Postbus 20244, 1000 HE Amsterdam, The Netherlands. Beral V, Peterman TA, Berkelman RL, Jaffe HW: Kaposi's sarcoma among persons with AIDS: a sexually

2 Beral V, Bull D, Darby S, et al. Risk of Kaposi's sarcomaO and sexual practices associated with faecal contact in homosexual or bisexual men with AIDS. Lancet 1992;339:632-5.

3 Van Griensven GJP, de Vroome EMM, Tielman RAP, etC al. Risk factors and prevalence of HIV antibodies among homosexual men in the Netherlands. Am 7 Epidemio@ homosexual men in

4 Lifson AR, Darrow WW, Hessol NA, et al. Kaposi's sarcoma in a cohort of homosexual men. Am $\mathcal{F}$ Epidemiole 1990;131:221-31.

5 Elford J, Tindall B, Sharkey T. Kaposi's sarcoma and insertive rimming. Lancet 1992;339:938.

6 Page-Bodkin K, Tappero J, Samuel M, Winkelstein W. Kaposi's sarcoma and faecal-oral exposure. Lancet 1992;339:1490.

Accepted for publication 8 September 1992.
Primary HIV-1 infection associated with prominent genital ulcers

Genital ulceration is a well-known risk factor for sexual HIV contamination, but has seldom been recorded in primary HIV infections. We report one such case.

A 30 year old heterosexual man, a drugaddict who used sterile material, consulted on the 24 January 1991 for sepsis. He had a 15 day history of tender genital ulcers, pharyngitis for 5 days, a diffuse scaly maculo-pustular rash for 1 day, and complained of general aching with persistent fever $\left(39^{\circ} \mathrm{C}\right)$, diarrhoea, nausea, vomiting and odynophagia.

He had a $3 \mathrm{~cm}$ ulcer and several smaller ulcers on the foreskin, along the corona of the glans prepuce. They were shallow, soft-based, ragged, whitish and surrounded by a red zone. In addition, round abrasions were scattered over the scrotum (fig). He was also suffering from thrush associated with round superficial ulcerations on the soft palate and inner cheeks. Neither nodes nor spleen were enlarged.

The blood cell counts indicated a pronounced lymphopenia $\left(0.72 \times 10^{9} / 1\right)$ and a mild thrombocytopenia. The sedimentation rate was $23 \mathrm{~mm}$ at one hour.

The diagnosis of Behcet's disease was excluded.

Blood and skin bacterial cultures were ster $=\frac{D}{0}$ ile. Tests for Treponema pallidum were carried out by dark-field microscopy of genital ando oral ulcers, VDRL (Venereal Disease Research ${ }^{N}$

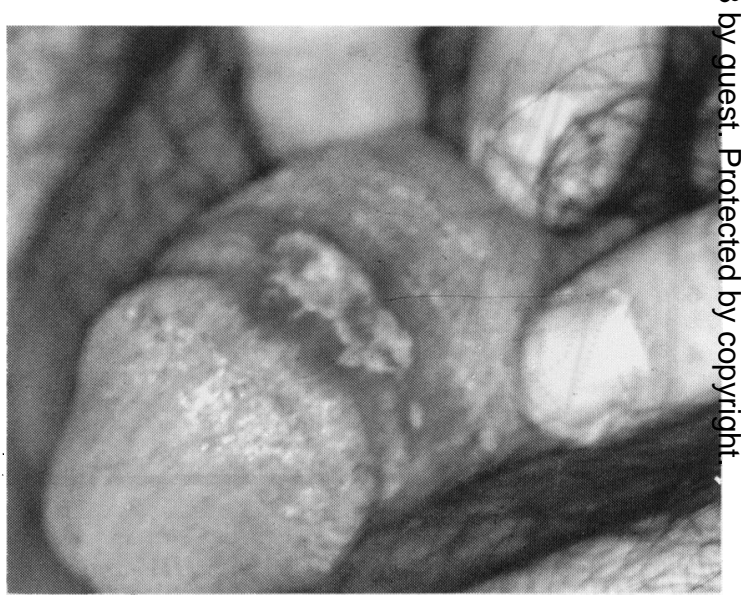

Figure Multiple genital ulcers. 